\title{
Recycling lithium-ion batteries from electric vehicles
}

https://doi.org/10.1038/s41586-019-1682-5

Received: 14 January 2019

Accepted: 23 July 2019

Published online: 6 November 2019

There are amendments to this paper

\author{
Gavin Harper 1,2,3*, Roberto Sommerville ${ }^{1,2,4}$, Emma Kendrick ${ }^{1,2,3}$, Laura Driscoll ${ }^{1,2,5}$, \\ Peter Slater ${ }^{1,2,5}$, Rustam Stolkin ${ }^{1,2,3,6}$, Allan Walton ${ }^{1,2,3}$, Paul Christensen ${ }^{1,7}$, Oliver Heidrich ${ }^{1,7,8}$, \\ Simon Lambert ${ }^{1,7}$, Andrew Abbott ${ }^{1,9}$, Karl Ryder ${ }^{1,9}$, Linda Gaines ${ }^{10}$ \& Paul Anderson ${ }^{1,2,5 *}$
}

Rapid growth in the market for electric vehicles is imperative, to meet global targets for reducing greenhouse gas emissions, to improve air quality in urban centres and to meet the needs of consumers, with whom electric vehicles are increasingly popular. However, growing numbers of electric vehicles present a serious waste-management challenge for recyclers at end-of-life. Nevertheless, spent batteries may also present an opportunity as manufacturers require access to strategic elements and critical materials for key components in electric-vehicle manufacture: recycled lithium-ion batteries from electric vehicles could provide a valuable secondary source of materials. Here we outline and evaluate the current range of approaches to electric-vehicle lithium-ion battery recycling and re-use, and highlight areas for future progress.

\begin{tabular}{l}
$\begin{array}{l}\text { Anniversary } \\
\text { collection: } \\
\text { go.nature.com/ } \\
\text { nature150 }\end{array}$ \\
\hline nature
\end{tabular}

The electric-vehicle revolution, driven by the imperatives to decarbonize personal transportation in order to meet global targets for reductions in greenhouse gas emissions and improve air quality in urban centres, is set to change the automotive industry radically. In 2017 , sales of electric vehicles exceeded one million cars per year worldwide for the first time ${ }^{1}$. Making conservative assumptions of an average battery pack weight of $250 \mathrm{~kg}$ and volume of half a cubic metre, the resultant pack wastes would comprise around 250,000 tonnes and half a million cubic metres of unprocessed pack waste, when these vehicles reach the end of their lives. Although re-use and current recycling processes can divert some of these wastes from landfill, the cumulative burden of electric-vehicle waste is substantial given the growth trajectory of the electric-vehicle market. This waste presents a number of serious challenges of scale; in terms of storing batteries before repurposing or final disposal, in the manual testing and dismantling processes required for either, and in the chemical separation processes that recycling entails.

Given that the environmental footprint of manufacturing electric vehicles is heavily affected by the extraction of raw materials and production of lithium ion batteries, the resulting waste streams will inevitably place different demands on end-of-life dismantling and recycling systems. In the waste management hierarchy, re-use is considered preferable to recycling (Fig.1). Because considerable value is embedded in manufactured lithium-ion batteries (LIBs), it has been suggested that their use should be cascaded through a hierarchy of applications to optimize material use and life-cycle impacts ${ }^{2}$. Markets for energy storage are under development as energy regulators in various locations transition to cleaner energy sources. Energy storage is particularly soughtafter in areas where weak grids require reinforcement, where high penetration of renewables requires supply to be balanced with demand, where there is an opportunity for trading energy with the grid and in offgrid applications. Second-use battery projects have started to develop in locations where there is regulatory and market alignment. However, large concentrations of waste-be it for refurbishment, re-manufacture, dismantling or final disposal-can create substantial challenges. A fire in stockpiled tyres in Powys, Wales, for example, smouldered for fifteen years from 1989 to 2004 . Since the electrode materials in LIBs are far more reactive than tyre rubber $^{3}$, without a proactive and economically sound waste-management strategy for LIBs there are potentially greater dangers associated with stockpiling of end-of-life LIBs. Already the number of fires being reported in metal-recovery facilities is increasing $^{4}$, owing to the illicit or accidental concealment of (consumer) LIBs in the guise of, for example, lead-acid batteries. Among examples of recent major fires are those that took place in metal-recovery facilities in Shoreway, San Carlos, USA, in September $2016^{5}$, Guernsey in August 2018 and Tacoma, Washington, USA, in September 2018.

Waste may also represent a valuable resource. Elements and materials contained in electric-vehicle batteries are not available in many nations and access to resources is crucial in ensuring a stable supply chain. In the future, electric vehicles may prove to be a valuable secondary resource for critical materials, and it has been argued that high-cobalt-content batteries should be recycled immediately to bolster cobalt supplies ${ }^{6}$. If tens of millions of electric vehicles are to be produced annually, careful husbandry of the resources consumed by electric-vehicle battery manufacturing will surely be essential to ensure the sustainability of the automotive industry of the future, as will a material- and energyefficient $3 R$ system (reduce, re-use, recycle). Here we give an overview

${ }^{1}$ Faraday Institution, ReLiB Project, University of Birmingham, Birmingham, UK. ${ }^{2}$ Birmingham Centre for Strategic Elements and Critical Materials, University of Birmingham, Birmingham, UK. ${ }^{3}$ School of Metallurgy and Materials, University of Birmingham, Birmingham, UK. ${ }^{4}$ School of Chemical Engineering, University of Birmingham, Birmingham, UK. ${ }^{5}$ School of Chemistry,

University of Birmingham, Birmingham, UK. ${ }^{6}$ National Centre for Nuclear Robotics, University of Birmingham, Birmingham, UK. ${ }^{7}$ School of Engineering, Newcastle University, Newcastle, UK. ${ }^{8}$ Tyndall Centre for Climate Change Research, Newcastle University, Newcastle, UK. ${ }^{9}$ Materials Centre, University of Leicester, Leicester, UK. ${ }^{10}$ ReCell Center, Argonne National Laboratory, Lemont, IL, USA. *e-mail: g.d.j.harper@bham.ac.uk; p.a.anderson@bham.ac.uk 


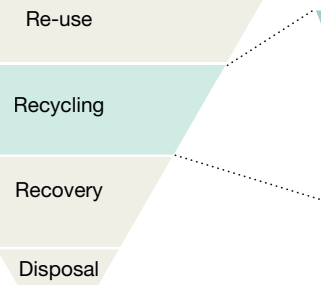

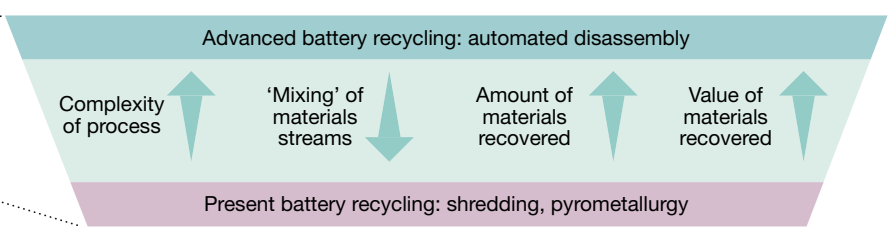

Fig. 1 | The waste management hierarchy and range of recycling options. The waste management hierarchy is a concept that was developed from the Council Directive 75/442/EEC of 15July 1975 (https://eur-lex.europa.eu/legal-content/ $\mathrm{EN} / \mathrm{TXT} /$ ?uri=CELEX\%3A31975L0442) on waste by the Dutch politician Ad Lansink, in 1979, who presented to the Dutch parliament a simple schematic representation that has been termed 'Lansink's Ladder', ranking waste management options from the most to least environmentally desirable options. Here, that hierarchy is expanded to consider the range of battery recycling technologies. 'Prevention' means that LIBs are designed to use less-critical

of the current state of the art and identify some of the important issues relating to the end-of-life management of electric-vehicle LIBs.

\section{Social and environmental impacts of LIBs}

If we consider the two main modes of primary production, it takes 250 tons of the mineral ore spodumene ${ }^{7,8}$ when mined, or 750 tons of mineral-rich brine ${ }^{7,8}$ to produce one ton of lithium. The processing of large amounts of raw materials can result in considerable environmental impacts 9 . Production from brine, for example, entails drilling a hole in the salt flat, and pumping of the mineral-rich solution to the surface. However, this mining activity depletes water tables. In Chile's Salar de Atacama, a major centre of lithium production, $65 \%$ of the region's water is consumed by mining activities ${ }^{9}$. This affects farmers in the region who must then import water from other regions. The demands on water from the processing of lithium produced in this way are substantial, with a ton of lithium requiring 1,900 tons of water to extract, which is consumed by evaporation?.

By contrast, secondary production would require only 28 tons of used $\mathrm{LIBs}^{7,8,10}$ (around 256 used electric-vehicle $\mathrm{LiBs}^{8}$ ). The net impact of LIB production can be greatly reduced if more materials can be recovered from end-of-life LIBs, in as close to usable form as possible ${ }^{11}$. However, in the rapid-growth phase of the electric-vehicle market, recycling alone cannot come close to replenishing mineral supplies ${ }^{12}$. LIBs are anticipated to last $15-20$ years ${ }^{12}$ based on calendar aging (the aging due to time since manufacture) predictions-three times longer than lead-acid batteries ${ }^{12}$. Initial concerns regarding resource constraints for LIB production scale-up focused on lithium ${ }^{13}$; however, in the near term, reserves of lithium are unlikely to present a constraint ${ }^{14,15}$.

Of greater immediate concern are cobalt reserves ${ }^{16}$, which are geographically concentrated (mainly in the politically unstable Democratic Republic of the Congo). These have experienced wild short-term price fluctuations and raise multifarious social, ethical and environmental concerns around their extraction, including artisanal mines employing child labour $^{17}$. In addition to the environmental imperative for recycling, there are clearly serious ethical concerns with the materials supply chain, and these social burdens are borne by some of the world's most vulnerable people. Given the global nature of the industry, this will require international coordination to support a concerted push towards recycling LIBs and a circular economy in materials ${ }^{18}$. materials (high economic importance, but at risk of short supply) and that electric vehicles should be lighter and have smaller batteries. 'Re-use' means that electric-vehicle batteries should have a second use. 'Recycling' means that batteries should be recycled, recovering as much material as possible and preserving any structural value and quality (for example, preventing contamination). 'Recovery' means using some battery materials as energy for processes such as fuel for pyrometallurgy. Finally, 'disposal' means that no value is recovered and the waste goes to landfill.

\section{Battery assessment and disassembly}

The waste-management hierarchy considers re-use to be preferable to recycling (Fig.1). As considerable value is embedded in manufactured LIBs, it has been suggested that their use should be cascaded through a hierarchy of applications to optimize material use and life-cycle impacts $^{2}$. Energy stored over energy invested (ESOI)-the ratio between the energy that must be invested into manufacturing the battery and the electrical energy that it will store over its useful life-is a metric used to compare the efficacy of different energy-storage technologies. Clearly, ESOI figures will improve if end-of-life electric-vehicle batteries can be used in second-use applications for which the battery performance is less critical.

Profitable second-use applications also provide a potential value stream that can offset the eventual cost of recycling, and already a healthy market is developing in used electric-vehicle batteries for energy storage in certain localities, with demand potentially outstripping supply. For the moment the economics of the decision whether to recycle or re-use are set firmly in favour of re-use. The main factors are (1) the refurbishment cost of putting the battery into a second-use application and (2) any credit that would accrue as the result of recycling the battery instead; if the second-use price were to fall below the sum of the refurbishment cost and the recycling credit, then recycling would be the economically favoured option ${ }^{19}$. In time, it is anticipated ${ }^{19}$ that the supply of used electric-vehicle batteries will far exceed the quantity that the second-use market can absorb. It must be remembered, therefore, that-if disposal to landfill is to be avoided-recycling must be the ultimate fate of all LIBs, even if they first have a second use.

Given that stockpiling of waste batteries is potentially unsafe and environmentally undesirable, if direct re-use of an LIB module is not possible, it must be repaired or recycled. End-of-life LIB recycling could provide important economic benefits, avoiding the need for new mineral extraction ${ }^{20}$ and providing resilience against vulnerable links ${ }^{21}$ and supply risks ${ }^{22}$ in the LIB supply chain. For most remanufacture and recycling processes, battery packs must be disassembled to module level at least. However, the hazards associated with battery disassembly are also numerous ${ }^{23,24}$. Disassembly of battery packs from automotive applications requires high-voltage training and insulated tools to prevent electrocution of operators or short-circuiting of the pack. Short-circuiting results in rapid discharge, which may lead to heating and thermal runaway. Thermal runaway may result in the generation of particularly noxious byproducts, including HF gas ${ }^{25}$, which along with 
other product gases may become trapped and ultimately result in cells exploding $^{23}$. The cells also present a chemical hazard owing to the flammable electrolyte, toxic and carcinogenic electrolyte additives, and the potentially toxic or carcinogenic electrode materials.

\section{Diagnostics of battery pack, modules and cells}

'State of health' is the degree to which a battery meets its initial design specifications. Over time as the battery degrades, its performance varies from its initial condition. The units are percentage points, with $100 \%$ indicating a state of health that is identical to that of a new battery meeting its design specification. (Some new batteries may leave the factory deviating from design specifications, and having less than $100 \%$ state of health.) The 'state of charge' is the degree to which a battery is charged or discharged. Again, the units are percentage points, with $0 \%$ indicating empty and $100 \%$ indicating full).

Battery repurposing-the re-use of packs, modules and cells in other applications such as charging stations and stationary energy storagerequires accurate assessment of both the state of health, to categorize whether batteries are best suited for re-use (and if so, for which applications), remanufacture or recycling, and the state of charge, for safety reasons in some recycling processes. For high-throughput triage and gateway testing of batteries at scale, the optimal approach involves in situ techniques for monitoring cells in service to enable advance warning of possible cell replacement, and module or pack reconditioning, rather than complete repurposing at a low level of state of health owing to a few failing cells.

Electrochemical impedance spectroscopy can give information on the state of health of cells, modules and, potentially, full packs ${ }^{26}$, and also an indication of aging mechanisms such as lithium plating. Such measurements have the potential to inform a decision matrix for re-use or disassembly and processing and, importantly, to identify potential hazards that would have further consequences for downstream processing. Electrochemical impedance spectroscopy has been researched for gateway testing in primary production, for example, in a large battery production plant in the $\mathrm{UK}^{27,28}$. A number of electric-vehicle manufacturers plan to use similar technologies to manage and maintain electricvehicle battery packs through the identification and replacement of failing modules in the field. Substantial advantages in cost, safety and throughput time are anticipated if this process can be mostly or fully automated $^{27,29}$. In future, more advanced diagnostic functionality will be embedded in battery management systems, providing data that can be interrogated at end-of-life.

\section{Challenges of pack and module disassembly}

Different vehicle manufacturers have adopted different approaches for powering their vehicles, and electric vehicles on the market possess a wide variety of different physical configurations, cell types and cell chemistries. This presents a challenge for battery recycling. Figure 2 details three different types of battery cell design, and their respective packs from electric vehicles in the marketplace from model year 2014. It can be seen that the three vehicles possess very different physical configurations, requiring different approaches for disassembly, particularly regarding automation. It can be seen in Fig. 2 that at the different scales of disassembly, the format and relative size of the different components differ, presenting challenges for automation. The differing form factors and capacities may also restrict applications for re-use. And finally, Fig. 2 illustrates that manufacturers employ varying cell chemistries (see Fig. 3 ), which will necessitate different approaches to materials reclamation and strongly affect the overall economics of recycling. Whereas the prismatic and pouch cells have planar electrodes, the cylindrical cells are tightly coiled, presenting additional challenges to separating the electrodes for direct recycling processes.

For repurposing and second-use applications, automotive battery packs are currently dismantled by hand for either the second use of the modules or for recycling. The weights and high voltages of traction batteries mean that qualified employees and specialized tools are required for such dismantling ${ }^{25}$. This is a challenge for an industry in transition with a shortage of skills. An Institute of the Motor Industry survey found only 1,000 trained technicians in the UK capable of servicing electric vehicles ${ }^{30}$, with another 1,000 in training. Given there are 170,000 motor technicians in the UK, this represents less than $2 \%$ of the workforce. There is concern that untrained mechanics may risk their lives repairing electric vehicles ${ }^{31}$, and these concerns logically extend to those handling vehicles at the end-of-life. Additionally, it has been suggested ${ }^{32}$ that manual dismantling, in countries with high labour costs, is uneconomic with respect to revenues from extracted materials or components. Vehicle design has to strike compromises between crash safety, centre of gravity and space optimization, which must be balanced against serviceability ${ }^{25}$. These conflicting design objectives often result in designs that are not optimized for recyclability, and that can be time-consuming to disassemble manually ${ }^{25}$.

\section{Automating battery disassembly}

Robotic battery disassembly could eliminate the risk of harm to human workers, and increased automation would reduce cost, potentially making recycling economically viable. This is being piloted in a number of current research projects ${ }^{33-36}$. Importantly, automation could also improve the mechanical separation of materials and components, enhancing the purity of segregated materials and making downstream separation and recycling processes more efficient. The automation of the dismantling of automotive batteries, however, presents major challenges. This is because robotics and automation in the manufacturing sector rely on highly structured environments, in which robots make preprogrammed repetitive actions with respect to exactly known objects in fixed positions. In contrast, the development of robotic systems that can generalize to a variety of objects, and handle uncertainty, remains a major challenge at the frontier of artificial intelligence research. It is important to consider the complexity of vehicle battery disassembly from this perspective.

At present there is no standardization ${ }^{37}$ of design for battery packs, modules or cells within the automotive sector, and it is unlikely that this will happen in the near future. Other battery-reliant products, such as mobile phones, have seen an exponential proliferation of different sizes, shapes and types of battery over the past two decades. At present, much of the factory assembly of these batteries is done by human workers and remains unautomated. Their disassembly and waste-handling typically involve even less structured environments, with much greater uncertainties, than a manufacturing assembly line.

Nevertheless, some progress has been made towards automated sorting of consumer batteries. The Optisort system ${ }^{38,39}$ uses computer vision algorithms to recognize the labels on batteries, and then pneumatic actuators to segregate batteries into different bins according to their type of chemistry. However, Optisort is currently limited to AA and AAA batteries, and a large amount of pre-sorting by hand is needed to separate these from mixed batches of waste batteries, prior to entering the Optisort machine.

The Society for Automotive Engineers and the Battery Association of Japan have both recommended labelling standards for electricvehicle batteries. Recent algorithms from computer vision research have some capability to recognize objects and materials on the basis of features such as size, shape, colour and texture. However, it could be advantageous for recycling if manufacturers were to (some manufacturers already do) include labels, QR Codes, RfID tags or other machinereadable features on key battery components and sub-structures. Where these provide a reference to an external data source, its utility in aiding the recycling process will depend on the accessibility and format of that data. If proprietary and private, such data are of limited use, but there may be initiatives to move towards standardization and open data formats. A number of companies are considering blockchain 


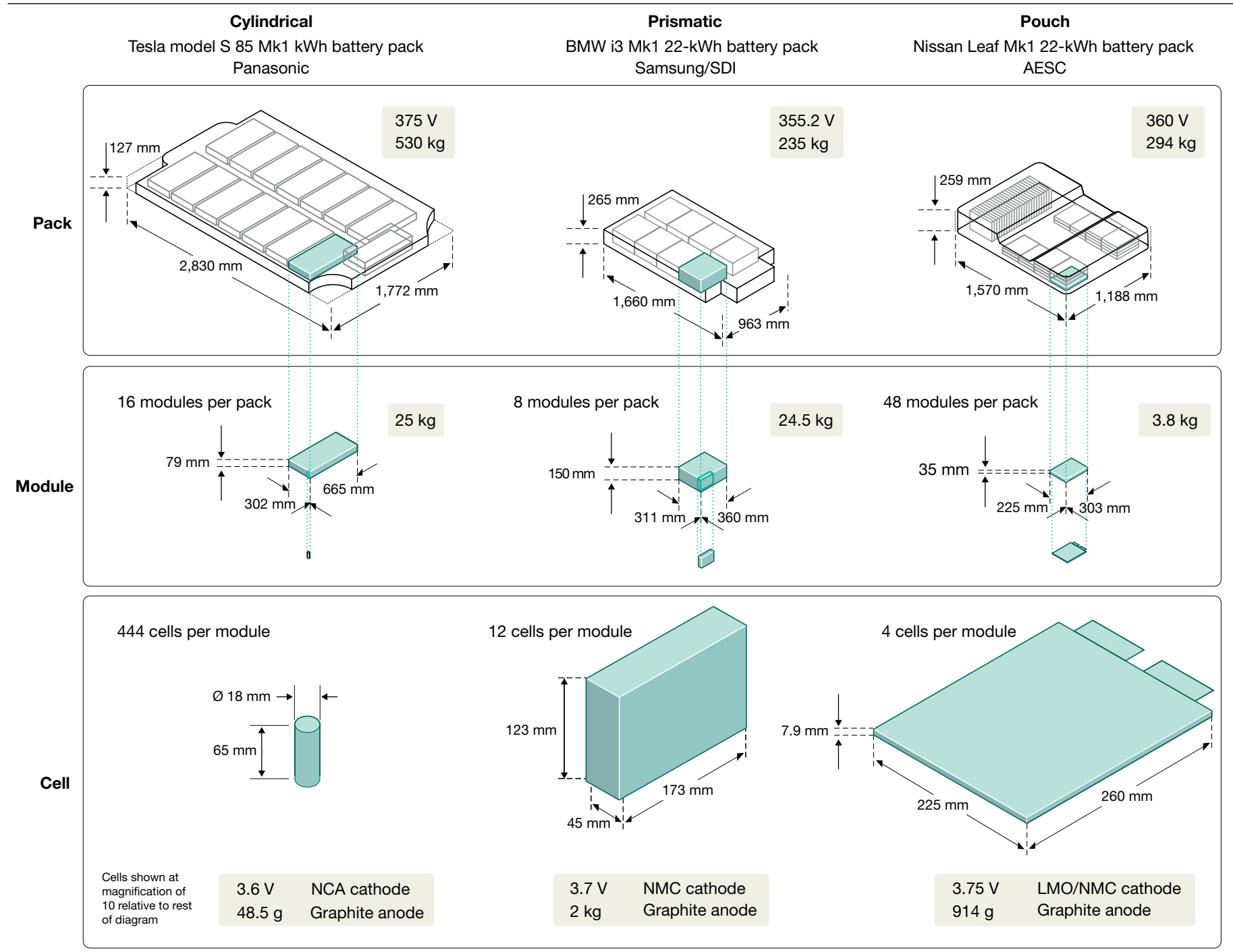

Fig. 2 | Examples of three different battery packs and modules (cylindrical, prismatic and pouch cells) in use in current electric cars. The three designs examined are from model year 2014; this is based on the availability of information from vehicle teardowns, and also because older vehicles are more likely to be closer to end-of-life than today's new cars. The breakdowns include material content in a cell, layout and content of the module and pack and the proportion of critical elements (high economic importance, but at risk of short supply) and strategic materials (either high economic importance or risk of short supply) used. The Nissan pouch cells from Automotive Energy Supply Corporation (AESC) exhibit a mixed cathode chemistry with substantial manganese content and relatively low levels of cobalt. The Tesla cylindrical 18650 cells from Panasonic and the BMW prismatic cells from Samsung SDI both

technologies to provide whole-life-cycle tracking of battery materials, including information and transparency on provenance, ethical supply chains, battery health and previous use ${ }^{40}$. China has signalled its intention to track battery materials.

Automated disassembly of electrical goods has also been implemented to some extent in other sectors. For example, Apple has implemented an automated disassembly line for the iPhone ${ }^{41}$ that can handle 1.2 million phones per year. This line has 22 stations linked on a conveyor system and can take the iPhone apart in 11 seconds. However, this system can only deal with an iPhone 6 model. Intact phones, of this exact model, must be positioned at the start of the disassembly line, which then uses pre-programmed motions of 29 robots in 21 different cells to dismantle the phone into 8 discrete parts. The LIB is removed by heating the glue which holds the battery in place. Owing to the potential fire hazard, contain high cobalt levels. Each cell has particular recycling challenges. Cylindrical cells are often bonded into a module using epoxy resin (difficult to remove or recycle); fuses at each end may be blown, making cell discharge challenging; and the cell geometry can be difficult to dismantle for direct recycling. Prismatic cells require 'can opening' (requiring special tools) to remove the contents. These large cells are under considerably more pressure than are the pouch or cylindrical cells, and can therefore be hazardous to open if the contents have degassed. The high manganese content of the Nissan pouch cells makes pyrometallurgical recycling less cost-effective, because manganese is cheap, but these cells are the least problematic to open and physically separate for direct recycling.

this must take place inside a thermal event protection system, while monitoring the battery using a thermal imaging system.

Unfortunately, 1.2 million phones per year is a drop in the ocean and the Apple disassembly line has been created using conventional industrial automation methods, making it inflexible and incapable of keeping up adaptively with new models and varieties of phones. But building a flexible and adaptable robot disassembly line need not be prohibitively expensive. The challenge is to create control algorithms and software that can make cheap hardware (robot arms cost only several thousands to several tens of thousands of dollars and costs have been steadily decreasing, can work all the time, and have very long service lifetimes) behave flexibly and intelligently to handle hugely complex disassembly problems. If those artificial intelligence challenges can be solved, then the capital investment required to respond to new and 


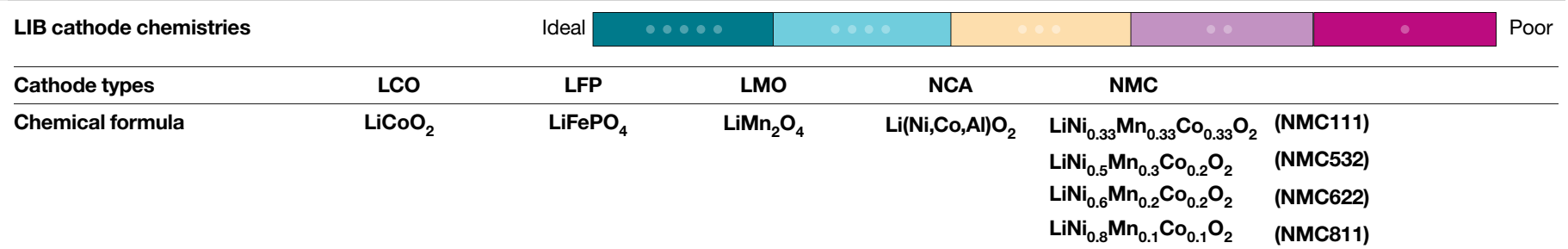

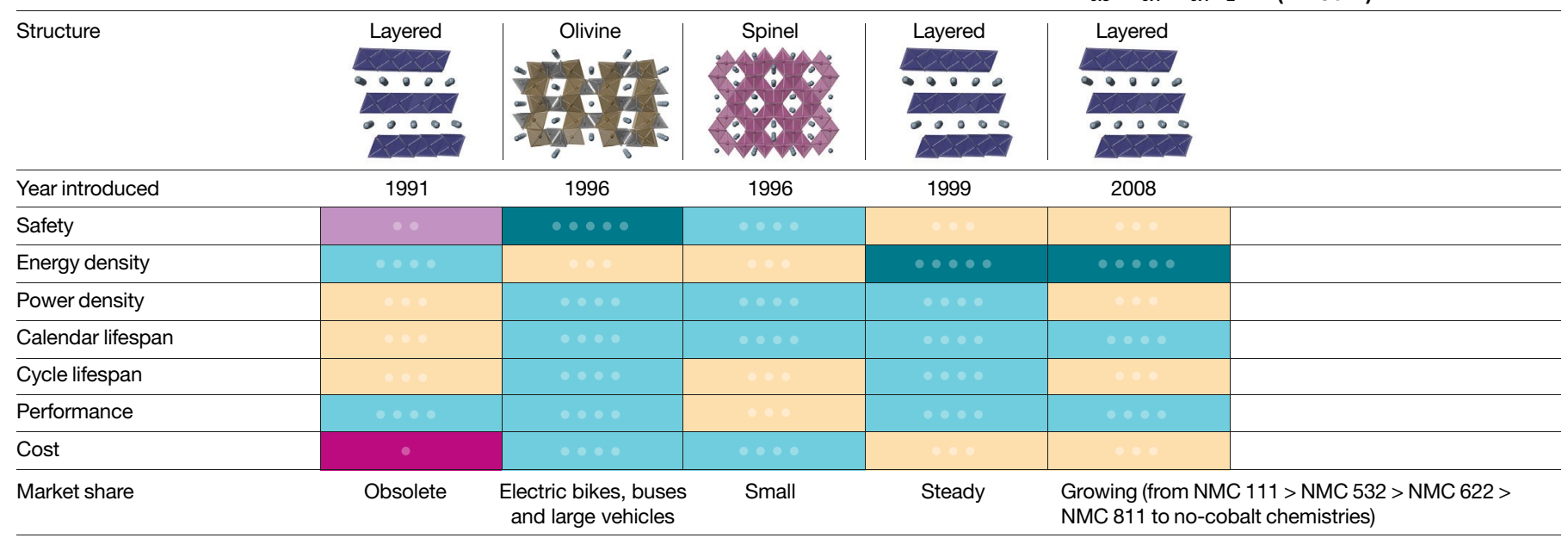

Fig. 3 | LIB cathode chemistries. The term LIB covers a range of different battery chemistries, each with different performance attributes. The basic concept of a LIB is that lithium can intercalate into and out of an open structure, which consists of either 'layers' or 'tunnels'. Generally the anode is graphite but the cathode material may have different chemistries and structures, which result in different performance attributes and there are trade-offs and compromises with each technology. The cathode chemistries of LIBs have a large impact on the performance of LIBs, and these chemistries have evolved and improved. Fig. 3 presents a summary of the different LiB cathode chemistries. changing models could be kept remarkably low (mainly software updates would be needed). Making robots behave intelligently will rely heavily on sensors to enable advanced robotic perception, especially computer vision using three-dimensional RGB-D imaging devices, combined with bespoke sensors from materials and battery experts. The robots will also require tactile and force-sensing capabilities to handle the complex dynamics problems of forceful interactions between the robots and the materials being disassembled.

Owing to the complexity of automotive battery packs, the possibility of collaborative human-robot co-working using a new generation of force-sensitive 'co-bot' robot arms ${ }^{33,42}$ has been suggested. Unlike conventional industrial robots, these co-bots can safely share a workspace with humans, and Wegener ${ }^{33}$ suggests that the robot could be taught tasks such as unscrewing bolts, while the human handles cognitively more complex tasks. However, this approach does not protect the human worker from battery hazards and even the task of locating a bolt, moving a tool to engage with it, unscrewing and removing it represents a cutting-edge research challenge in robotics and machine vision. Using current industrial robotics methods, the problem only becomes attemptable (but still difficult) provided that the position of the bolt head is always exactly fixed, in a known pose relative to the robot, with very high precision.

State-of-the-art robotics, computer vision and artificial-intelligence capabilities for handling diverse waste materials do exist, and these systems have demonstrated sufficient robustness and reliability to gain acceptance by the UK nuclear industry, for example, in the deployment of artificial-intelligence-controlled, machine-vision-guided robotic manipulation for cutting of contaminated waste material in radioactive environments ${ }^{43}$. These technologies are now being adapted to the demanding problem of robotic battery disassembly. At different scales of disassembly-pack removal, pack disassembly, module removal and cell separation-different challenges and barriers to automation exist. Some of these are set out in Fig. 4. Computer-vision algorithms are being developed that can identify diverse waste materials and objects ${ }^{44}$, reliably track objects in complex, cluttered scenes ${ }^{45}$, and dynamically guide the actions of robot $\mathrm{arms}^{46}$. Dismantling requires forceful interaction between robots and objects, engendering complex dynamics and control problems, such as simultaneous force and motion control ${ }^{47}$, which is needed for robotic cutting or unscrewing. Dismantled materials must be grasped and manipulated, including fragmented or deformable materials, which pose challenges both to vision systems and autonomous grasp planners. Adjigble et al..$^{48}$ have recently demonstrated state-of-the-art performance in autonomous, vision-guided robotic grasping of arbitrary objects from random, cluttered heaps. These advances in computer vision, artificial intelligence and robotics fundamentals offer exceptionally promising tools with which to approach the extremely difficult open research challenge of automated disassembly of electric-vehicle batteries.

\section{Stabilization and passivation of end-of-life batteries}

Once LIBs have been designated for recycling, the three main processes involved consist of stabilization, opening and separation, which may be carried out separately or together. Stabilization of the LIB can be achieved through brine or Ohmic discharge. In-process stabilization during opening, however, is the current route preferred in industry, as it minimizes costs. This consists of shredding or crushing the batteries in an inert gas such as nitrogen, carbon dioxide, or a mixture of carbon dioxide and argon. State-of-the art physical processing of LIBs in Europe and North America includes the Recupyl ${ }^{8}$ (France), Akkuser ${ }^{49}$ (Finland), Duesenfeld $^{50}$ (Germany) and Retriev ${ }^{51}$ (USA/Canada) processes. Largescale European processes do not currently use stabilization techniques prior to breaking cells open, instead opting for opening under an inert atmosphere of carbon dioxide or argon (with less than $4 \%$ molecular oxygen). Opening under carbon dioxide allows for the formation of a passivating layer of lithium carbonate on any exposed lithium metal. The Retriev process differs from the European processes in that it uses 
isassembly problems

- Variety of vehicle shapes and sizes

- Different pack configurations and locations

- Different fixings and tooling required

Bolts and fixings may be rusted

Heads of fixings may be rounded or sheared

- Position of bolt heads not always fixed

- Vehicle bodywork may be distorted

- Vehicle may be crash damaged

Pack removal

- Weight of battery

Recovered components

- Bus bars

- Electronics

- Wiring looms

- Modules > Cells

- Other components

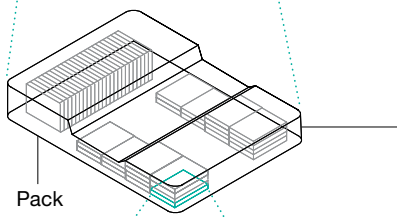

Removal of wiring looms trick

- Manipulation of connectors (especially where locking tabs fitted)

- High voltages until wiring loom/module links removed

- Lack of data on module condition in many electric-vehicle batteries

- Lack of labelling and identifying marks

- Potential fire hazards

- Potential offgassing of HF
Recovered components

- Casings

- Terminals

- Cells

$\begin{array}{ll}\text { Recovered materials } \\ \text { (depending on cell chemistry } \\ \text { and recycling process) } \\ \text { - Cobalt } \quad \text { - Manganese } \\ \text { - Nickel } & \text { - Aluminium } \\ \text { - Lithium } & \text { - Plastics } \\ \text { - Graphite } & \end{array}$

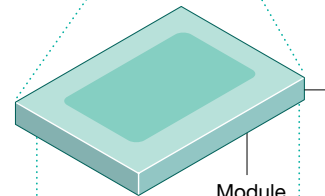

Module

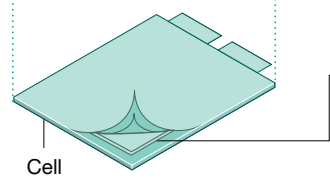

Fig. 4 | Diagram showing challenges of disassembly at different levels of scale. Electric-vehicle battery packs are complex in design, containing wiring looms, bus bars, electronics, modules, cells and other components. There are
- Clean separation of anodes and cathode for direct recycling difficult - Very finely powdered materials present risks (nanoparticles)

- Potential for HF compounds formed from electrolyte

- Potential for thermal effects if cells shorted during disassembly

- Chemistries not always known or may be proprietary

- Additional challenges with cylindrical cells (unwinding spiral)

also many different types of fixtures and fastenings, including screws, bolts, adhesives, sealants and solders, which are not designed for robotic removal.

the cost-effectiveness of the process ${ }^{54}$. The downside, however, is that contamination of the cell contents threatens to complicate the downstream chemical processes or compromise the value of processed materials streams.

An alternative to the use of salt solutions is direct Ohmic discharge of the battery through a load-bearing circuit. If the electricity can be reclaimed from the discharge, this could offset some of the cost of further processing. To put it into context, the domestic consumption of a standard UK home is up to $4,600 \mathrm{kWh}$ per year. So a $60-\mathrm{kWh}$ battery pack at a $50 \%$ state of charge and a $75 \%$ state of health has a potential $22.5 \mathrm{kWh}$ for end-of-life reclamation, which would power a UK home for nearly 2 hours. At 14.3 p per kWh, this equates to UK£3.22 per pack, which may seem a modest gain that does not warrant the cost of investing in equipment. However, if it is unrecovered, the energy from discharge must be dissipated, and this will add to the cooling burden of the facility, creating additional costs. Furthermore, an economy of scale is to be anticipated when recycling electric vehicle batteries in bulk. Similarly, reclaimed energy might make a useful contribution to the profitability of repurposing for second use (see section 'Battery assessment and disassembly').

LIB cells can be shredded at various states of charge, and from a commercial point of view, if discharged modules or cells are to be processed in this way, discharge prior to shredding adds cost to the processes. Furthermore, exactly what the optimum level of discharge might be remains unclear. Depending on cell chemistry and depth of discharge, over-discharging of cells can result in copper dissolution into the electrolyte. The presence of this copper is detrimental for materials reclamation as it may then contaminate all the different materials streams, including the cathode and separator. If the voltage is then increased again or 'normal' operation resumed ${ }^{55}$, this can be dangerous because 
copper can reprecipitate throughout the cell, increasing the risks of short-circuiting and thermal runaway.

Current LIB-processing technologies essentially bypass these concerns by feeding end-of-life batteries directly into a shredder or high-temperature reactor. Industrial comminution technologies can passivate batteries directly but recovered battery materials then require a complex set of physical and chemical processes to produce usable materials streams. Pyrometallurgical recycling processes (see section 'Stabilization and passivation of end-of-life batteries') at scale may be able to accept entire electric-vehicle modules without further disassembly. However, this solution fails to capture much of the embodied energy that goes into LIB manufacture, and leaves chemical separation techniques with much to do as the battery materials become ever more intimately mixed.

\section{Recycling methods}

\section{Pyrometallurgical recovery}

Pyrometallurgical metals reclamation uses a high-temperature furnace to reduce the component metal oxides to an alloy of $\mathrm{Co}, \mathrm{Cu}, \mathrm{Fe}$ and $\mathrm{Ni}$. The high temperatures involved mean that the batteries are 'smelted', and the process, which is a natural progression from those used for other types of batteries, is already established commercially for consumer LIBs. It is particularly advantageous for the recycling of general consumer LIBs, which currently tends to be geared towards an imperfectly sorted feedstock of cells (indeed, the batteries can be processed along with other types of waste to improve the thermodynamics and products obtained), and this versatility is also valuable with respect to electricvehicle LIBs. As the metal current collectors aid the smelting process ${ }^{56}$, the technique has the important advantage that it can be used with whole cells or modules, without the need for a prior passivation step.

The products of the pyrometallurgical process are a metallic alloy fraction, slag and gases. The gaseous products produced at lower temperatures $\left(<150^{\circ} \mathrm{C}\right)$ comprise volatile organics from the electrolyte and binder components. At higher temperatures the polymers decompose and burn off. The metal alloy can be separated through hydrometallurgical processes (see section 'Hydrometallurgical metals reclamation') into the component metals, and the slag typically contains the metals aluminium, manganese and lithium, which can be reclaimed by further hydrometallurgical processing, but can alternatively be used in other industries such as the cement industry. There is relatively little safety risk in this process, as the cells and modules are all taken to extreme temperatures with a reductant for metal reclamation-aluminium from the electrode foils and packaging is a major contributor here-so the hazards are contained within the processing. In addition, the burning of the electrolytes and plastics is exothermic and reduce the energy consumption required for the process. It follows that in the pyrometallurgical process there is typically no consideration given to the reclamation of the electrolytes and the plastics (approximately 40-50 per cent of the battery weight) or other components such as the lithium salts. Despite environmental drawbacks (such as the production of toxic gases, which must be captured or remediated and the requirement for hydrometallurgical post-processing), high energy costs, and the limited number of materials reclaimed, this remains a frequently used process for the extraction of high-value transition metals such as cobalt and nickel ${ }^{57}$.

\section{Physical materials separation}

For reclamation after comminution, recovered materials can be subjected to a range of physical separation processes that exploit variations in properties such as particle size, density, ferromagnetism and hydrophobicity. These processes include sieves, filters, magnets, shaker tables and heavy media, used to separate a mixture of lithium-rich solution, lowdensity plastics and papers, magnetic casings, coated electrodes and electrode powders. The result is generally a concentration of electrode coatings in the fine fractions of material, and a concentration of plastics, casing materials, and metal foils in the coarse fractions ${ }^{58}$. The coarse fractions can be put through magnetic separation processes to remove magnetic material such as steel casings and density separation processes to separate plastics from foils. The fine product is referred to as the 'black mass', and comprises the electrode coatings (metal oxides and carbon). The carbon can be separated from metal oxides by froth flotation, which exploits the hydrophobicity of carbon to separate it from the more hydrophilic metal oxides ${ }^{59}$. An overview of how these processes are used by several companies is shown in Fig. 5, which mentions the Recupyl ${ }^{8}$ (France), Akkuser ${ }^{49}$ (Finland), Duesenfeld ${ }^{50}$ (Germany) and Retriev ${ }^{51}$ (USA/Canada) processes.

Often, the polymeric binders from the 'black mass' components need to be eliminated to liberate the graphite and metal oxides from the copper and aluminium current collectors. Published routes include the use of sonication in a solvent such as $N$-methyl-2-pyrrolidone (NMP) or dimethylformamide (DMF) to detach the cathode from the current collector $^{60}$, thermal heat treatment to decompose the binder ${ }^{61,62}$, or dissolution of the aluminium current collector ${ }^{63}$. These processes, however, often require high temperatures $\left(60-100^{\circ} \mathrm{C}\right)$ and are relatively slow $(3 \mathrm{~h})$. While ultrasound can induce faster delamination $(1.5 \mathrm{~h})$, this is still too slow for a continuous-flow process and the required solventto-solid mass ratios of 10:1 will not be viable on a commercial scale with these solvents ${ }^{64}$.

Recent teardowns of cells indicate that manufacturers are transitioning away from fluorinated binders. Many newer batteries are moving toward alternative binders on the anode, such as carboxymethyl cellulose (CMC), which is water-soluble, and styrene butadiene rubber (SBR), which is not water-soluble but is applied as an emulsion that may be easier to remove at end-of-life. There is also work on water-based binder systems for cathodes, but this is proving to be more challenging. Other studies have used cellulose- and lignin-based binders, although many of these are still in the laboratory testing phase ${ }^{65}$.

\section{Hydrometallurgical metals reclamation}

Hydrometallurgical treatments involve the use of aqueous solutions to leach the desired metals from cathode material. By far the most common combination of reagents reported is $\mathrm{H}_{2} \mathrm{SO}_{4} / \mathrm{H}_{2} \mathrm{O}_{2}$ (ref. ${ }^{66}$ ). A number of studies have been carried out in order to determine the most efficient set of conditions to achieve an optimal leaching rate. These include: concentration of leaching acid, time, temperature of solution, the solidto-liquid ratio and the addition of a reducing agent ${ }^{67}$. In most of these studies, it was found that leaching efficiency improved when $\mathrm{H}_{2} \mathrm{O}_{2}$ was added. Somewhat counterintuitively, it is understood that $\mathrm{H}_{2} \mathrm{O}_{2}$ acts as a reducing agent to convert insoluble $\mathrm{Co}$ (III) materials into soluble $\mathrm{Co}(\mathrm{II})$ through the reaction ${ }^{7}$ :

$$
2 \mathrm{LiCoO}_{2}(\mathrm{~s})+3 \mathrm{H}_{2} \mathrm{SO}_{4}+\mathrm{H}_{2} \mathrm{O}_{2} \rightarrow 2 \mathrm{CoSO}_{4}(\mathrm{aq})+\mathrm{Li}_{2} \mathrm{SO}_{4}+4 \mathrm{H}_{2} \mathrm{O}+\mathrm{O}_{2}
$$

A range of other possible leaching acids and reducing agents have been investigated ${ }^{68-72}$. The leached solution may also subsequently be treated with an organic solvent to perform a solvent extraction ${ }^{73-75}$. Once leached, the metals may be recovered through a number of precipitation reactions controlled by manipulating the $\mathrm{pH}$ of the solution. Cobalt is usually extracted either as the sulfate, oxalate, hydroxide or carbonate $^{75-79}$, and then lithium can be extracted through a precipitation reaction forming $\mathrm{Li}_{2} \mathrm{CO}_{3}$ or $\mathrm{Li}_{3} \mathrm{PO}_{4}^{80,81}$. An alternative recycling method describes mechanochemical treatment of materials, where electrode materials are ground with a chlorine compound or complexing agent to produce water-soluble salts of cobalt, which can be separated from insoluble fractions by washing with water ${ }^{82,83}$.

Most current recycling processes fall under the umbrella of 'reagent recovery' because the materials, with sufficient purity, can be re-used not just for resynthesizing the original cathode materials, but also in a range of other applications, such as the synthesis of $\mathrm{CoFe}_{2} \mathrm{O}_{4}$ or $\mathrm{MnCo}_{2} \mathrm{O}_{4}$ (refs. ${ }^{84-86}$ ). Following initial work focused on the leaching and 


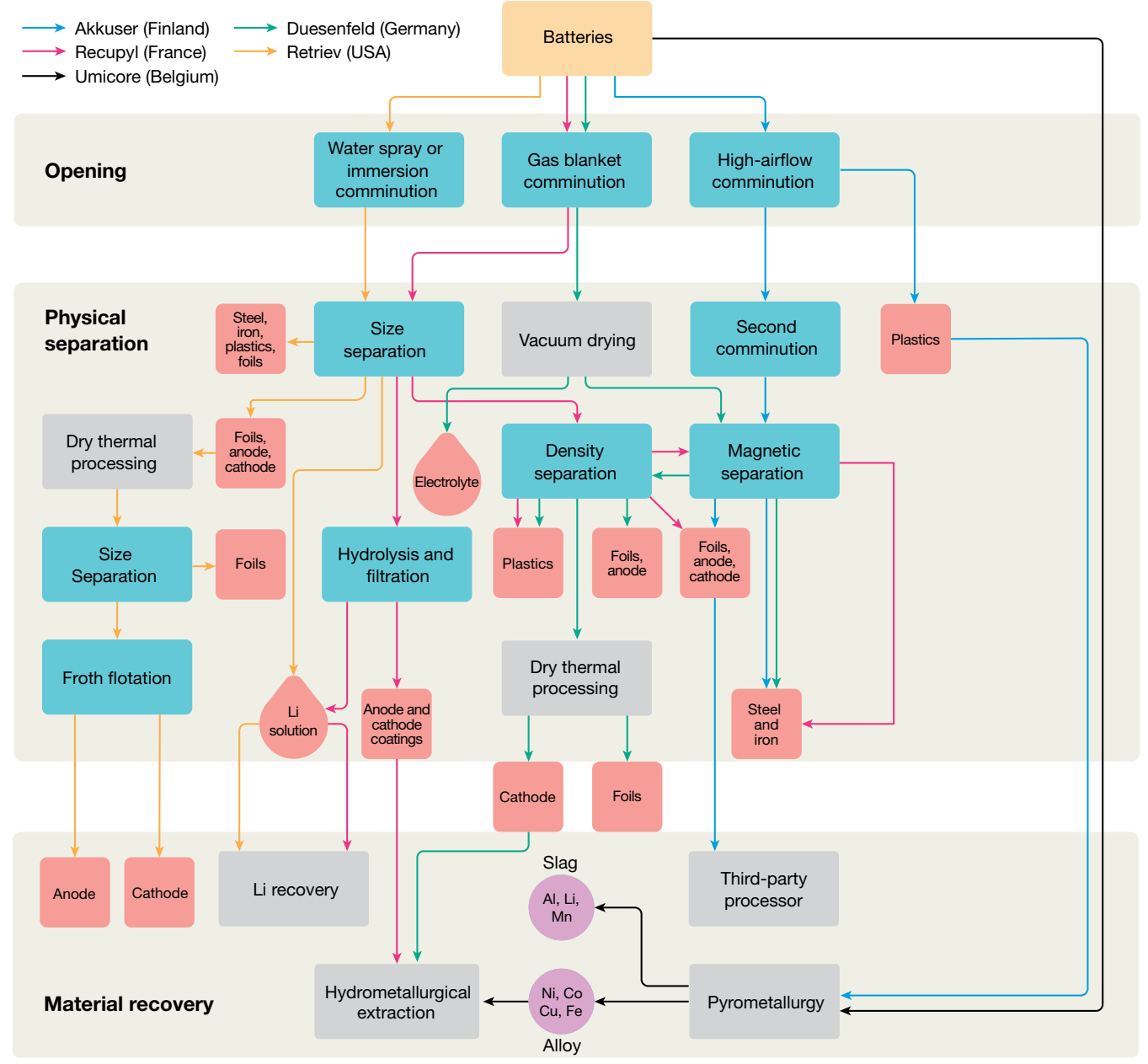

Fig. 5 | Flow chart representing potential routes for the circular economy of LIBs, detailing second-use applications, re-use, physical recovery, chemical recovery and biorecovery. A range of commercial entities have

remanufacture of $\mathrm{LiCoO}_{2}$ (ref. ${ }^{87}$ ), work has since moved on to strategies for new cell chemistries, which typically contain multiple transition metals (for example, $\mathrm{LiNi}_{1-x-y} \mathrm{Mn}_{x} \mathrm{Co}_{y} \mathrm{O}_{2} ; \mathrm{NMC}$ ). In such cases, once the metals have been leached from the cathode material, either sequential precipitation is employed to recover the individual metals, or the direct remanufacture of the cathode is targeted, such as work to recover $\mathrm{NMC}^{88}$. In this work, after leaching the metals from the cathode, the concentrations of the various metals in solution were measured and adjusted to match those in the target material (1:1:1 Ni:Mn:Co for NMC-111). The same group has applied the technique to NMC with varying metal contents and successfully resynthesized such $\mathrm{NMC}$ materials through the production of a precursor hydroxide, $\mathrm{Ni}_{x} \mathrm{Mn}_{y} \mathrm{Co}_{z}(\mathrm{OH})_{2}$ with $x, y$ and $z$ varying according to the desired final composition of the cathode ${ }^{89}$.

Other groups have published similar recovery methods with modifications such as additional solvent extraction steps ${ }^{90}$, lactic acid or urea as an alternative to sulfuric acid (additionally facilitating resynthesis) (1,92 $^{91}$ well as investigating the effect of magnesium in the resynthesized material $^{93}$. The big issues to be addressed with all solvo-metallurgical processes are the volumes of solvents required, the speed of delamination, the costs of neutralization and the likelihood of cross-contamination of materials. Although shredding is a fast and efficient method of rendering the battery materials safe, mixing the anode and cathode materials at the start of the recycling process complicates downstream processing. A method in which anode and cathode assemblies could be separated prior to mechanical or solvent-based separation would greatly improve material segregation. This is one of several key areas where designing commercialized processes for recycling LIBs. Different approaches for the physical separation of batteries and the recovery of materials are indicated. for end-of-life recycling promises to have a real impact, but the historic backlog of batteries containing polyvinylidene fluoride (PVDF) as a binder will still need to be processed. It is clear that the current design of cells makes recycling extremely complex and neither hydro-nor pyrometallurgy currently provides routes that lead to pure streams of material that can easily be fed into a closed-loop system for batteries.

\section{Direct recycling}

The removal of cathode or anode material from the electrode for reconditioning and re-use in a remanufactured LIB is known as direct recycling. In principle, mixed metal-oxide cathode materials can be reincorporated into a new cathode electrode with minimal changes to the crystal morphology of the active material. In general, this will require the lithium content to be replenished to compensate for losses due to degradation of the material during battery use and because materials may not be recovered from batteries in the fully discharged state with the cathodes fully lithiated. So far, work in this area has focused primarily on laptop and mobile phone batteries, as a result of the larger amounts of these available for recycling ${ }^{38}$. An example of how this recycling route could work has been outlined recently ${ }^{94}$. Cathode strips, obtained after dismantling spent batteries, were soaked in NMP before undergoing sonication. Powders were either regenerated through simple solid-state synthesis with the addition of fresh $\mathrm{Li}_{2} \mathrm{CO}_{3}$ or treated hydrothermally with a solution containing $\mathrm{LiOH} / \mathrm{Li}_{2} \mathrm{SO}_{4}$ before annealing.

For high-cobalt cathodes such as lithium cobalt oxide (LCO) conventional pyrometallurgical (see section 'Pyrometallurgical recovery') or 


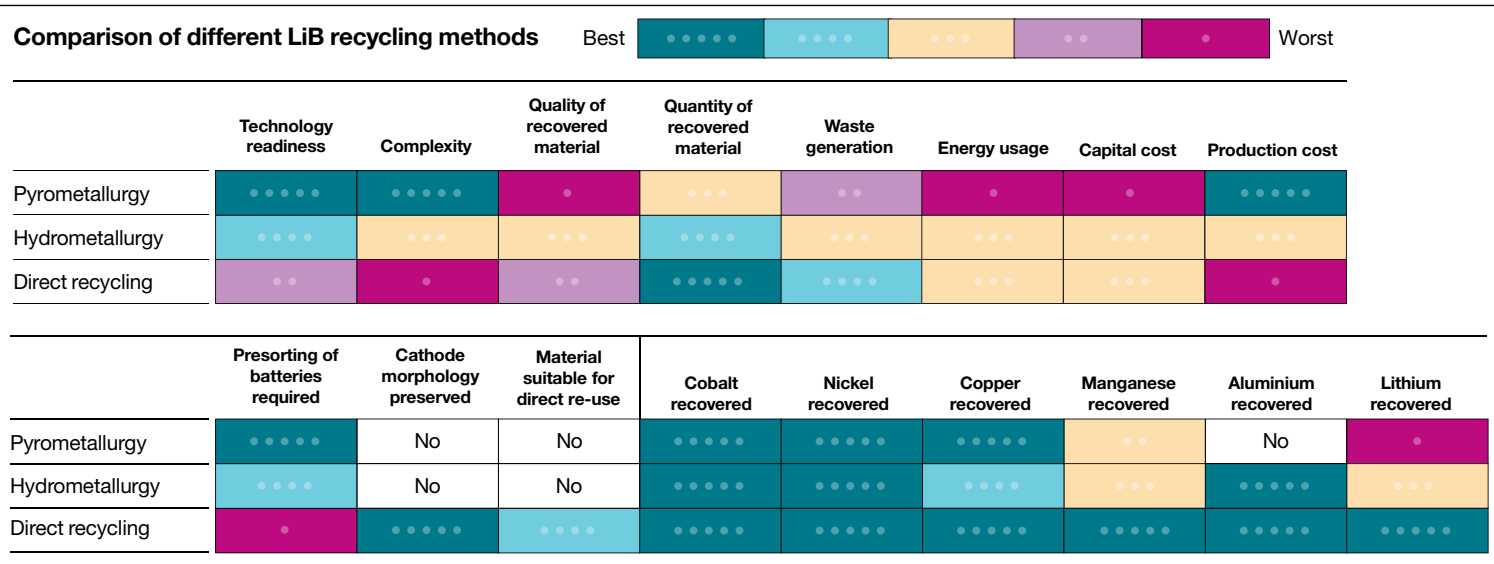

Fig. $6 \mid$ Comparison of different LiB recycling methods.

hydrometallurgical (see section 'Hydrometallurgical recovery') recycling processes can recover around $70 \%$ of the cathode value ${ }^{11}$. However, for other cathode chemistries that are not as cobalt-rich, this figure drops notably ${ }^{11}$. A 2019648 -lb Nissan Leaf battery, for example, costs US $\$ 6,500-8,500$ new, but the value of the pure metals in the cathode material is less than US $\$ 400$ and the cost of the equivalent amount of NMC (an alternative cathode material) is in the region of US $\$ 4,000$. It is important, therefore, to appreciate that cathode material must be directly recycled (or upcycled) to recover sufficient value. As direct recycling avoids lengthy and expensive purification steps, it could be particularly advantageous for lower-value cathodes such as $\mathrm{LiMn}_{2} \mathrm{O}_{4}$ and $\mathrm{LiFePO}_{4}$, where manufacturing of the cathode oxides is the major contributor to cathode costs, embedded energy and carbon dioxide footprint ${ }^{95}$.

Direct recycling also has the advantage that, in principle, all battery components ${ }^{20}$ can be recovered and re-used after further processing (with the exclusion of separators). Although there is substantial literature regarding the recycling of the cathode component from spent LIBs, research on recycling of the graphitic anode is limited, owing to its lower recovery value. Nevertheless, the successful re-use of mechanically separated graphite anodes from spent batteries has been demonstrated, with similar properties to that of pristine graphite ${ }^{96}$.

Despite the potential advantages of direct recycling, however, considerable obstacles remain to be overcome before it can become a practical reality. The efficiency of direct recycling processes is correlated with the state of health of the battery and may not be advantageous where the state of charge is low ${ }^{97}$. There are also potential issues with the flexibility of these routes to handle metal oxides of different compositions. For maximum efficiency, direct recycling processes must be tailored to specific cathode formulations, necessitating different processes for different cathode materials ${ }^{97}$. The ten or so years spent in a vehicle-followed, perhaps, by a few more in a second-use application-therefore present a challenge in an industry where battery formulations are evolving at a rapid pace. Direct recycling may struggle to accommodate feedstocks of unknown or poorly characterized provenance, and there will be commercial reluctance to re-use material if product quality is affected.

The direct recycling route for cathode coatings is also highly sensitive to contamination by other metals, such as aluminium, which results in poor electrochemical performance ${ }^{60}$. In particular, methods of recovering materials for further physical or chemical separation that involve a high degree of comminution form fine particles of $\mathrm{Al}$ and $\mathrm{Cu}$, which are difficult to separate from the electrode coatings. For this reason, processes that do not mechanically stress the electrode foils are favoured in direct recycling, and separation of the materials streams prior to mechanical sorting is preferable. However, methods of removing the electrode binder-typically pyrolysis or dissolution-present further challenges, such as the production of hazardous byproducts such as HF from pyrolysis of the PVDF binder or the use of the highly toxic NMP as a solvent for dissolution. The potential for the undesirable reaction of the PVDF binder with the electrode material appears to be a notable omission in the recycling literature, despite a growing body of research illustrating that PVDF is an excellent low-temperature fluorinating reagent for metal oxides ${ }^{98}$. Furthermore, recent research suggests that a certain degree of reaction can occur with the cathode even under conditions of normal cell operation ${ }^{99}$.

\section{Biological metals reclamation}

Bioleaching, in which bacteria are harnessed to recover valuable metals, has been used successfully in the mining industry ${ }^{100,101}$. This is an emerging technology for LIB recycling and metal reclamation and is potentially complementary to the hydrometallurgical and pyrometallurgical processes currently used for metal extraction ${ }^{102,103}$; cobalt and nickel, in particular, are difficult to separate and require additional solvent-extraction steps. The process uses microorganisms to digest metal oxides from the cathode selectively ${ }^{104}$ and to reduce these oxides to produce metal nanoparticles ${ }^{105,106}$. The number of studies that have been performed thus far, however, is relatively small and there is plenty of opportunity for further investigation in this field. The recycling methods discussed are compared in Fig. 6.

\section{Summary and opportunities}

The electric-vehicle revolution is set to change the automotive industry radically, and some of the most profound changes will inevitably relate to the management and decommissioning of vehicles at end-of-life. Of chief concern are the complex, high-tech power trains and, in particular, the LIBs. To put this into perspective, electrification of only $2 \%$ of the current global car fleet would represent a line of cars-and in due course, of end-of-life waste-that could stretch around the Earth. There is wide acceptance that, for environmental and safety reasons, stockpiling (or worse, landfill) and wholesale transport of end-of-life electric-vehicle batteries are not attractive options, and that the management of endof-life electric-vehicle waste will require regional solutions.

In the waste management hierarchy, re-use is considered preferable to recycling, in order to extract maximum economic value and minimize environmental impacts. Many companies in various parts of the world are already piloting the second use of electric-vehicle LIBs for a range of energy storage applications. Advanced sensors and improved methods of monitoring batteries in the field and end-of-life testing would enable the characteristics of individual end-of-life batteries to be better matched to proposed second-use applications, with concomitant advantages in lifetime, safety and market value. Even if all the benefits of 


\section{Review}

second-use are realized, however, it must be remembered that recycling (if not landfill) is the inevitable fate of all batteries.

Some recent life-cycle analyses has indicated that the application of current recycling processes to the present generation of electric-vehicle LIBs may not in all cases result in reductions in greenhouse gas emissions compared to primary production ${ }^{107}$. More efficient processes are urgently needed to improve both the environmental and economic viability of recycling, which at present is heavily dependent on cobalt content. However, as the amount of cobalt in cathodes is reduced for economic and other reasons, to recycle using current methods will become less advantageous owing to the lower value of the materials recovered.

At present, there are low volumes of electric-vehicle batteries that require recycling. As these volumes increase dramatically, there are questions concerning the economies (and diseconomies) of scale in relation to recycling operations ${ }^{58}$. Pyrometallurgical routes, in particular, suffer from high capital costs, and if full recyclability of LIBs is to be achieved, alternative methods are urgently required, rather than seeking to recycle only the most economically valuable components.

There are a number of lessons that the future LIB recycling industry could learn from the highly successful lead-acid battery recycling industry. As a technology, lead-acid batteries are relatively standardized and simple to disassemble and recycle, which minimizes costs, allowing the value of lead to drive recycling. Unfortunately, for a rapidly developing technology such as electric-vehicle LIBs, such advantages are not likely to apply any time soon.

A number of improvements could make electric-vehicle LIB recycling processes economically more efficient ${ }^{23}$, such as better sorting technologies, a method for separating electrode materials, greater process flexibility, design for recycling, and greater manufacturer standardization of batteries. There is a clear opportunity for a more sophisticated approach to battery recovery through automated disassembly, smart segregation of different batteries and the intelligent characterization, evaluation and 'triage' of used batteries into streams for remanufacture, re-use and recycling. The potential benefits of this are many and include reduced costs, higher value of recovered material streams, and the near elimination of the risk of harm to human workers.

The design of current battery packs is not optimized for easy disassembly. Use of adhesives, bonding methods and fixtures do not lend themselves to easy deconstruction either by hand or machine. All reported current commercial physical cell-breaking processes employ shredding or milling with subsequent sorting of the component materials. This makes the separation of the components more difficult than if they were presorted and considerably reduces the economic value of waste material streams. Many of the challenges this presents to remanufacture, re-use and recycling could be addressed if considered early in the design process.

For direct recycling where purity of the recovered materials is required, a process which involves less component contamination during the breaking stage is important. This would benefit from an analysis of the cell component chemistries, and the state of charge and state of health of the cells before disassembly into the component parts, rather than the production of a mixture of all components. At present, this separation has only been performed at a laboratory scale and usually employs manual disassembly methods that are difficult to scale up economically. The move to greater automation and robotic disassembly promises to overcome some of these hurdles. Issues regarding the binder still need to be resolved, and acid, alkali, solvent and thermal treatments all have their positives and negatives. A cell design for reclamation of materials is extremely appealing, with low-cost water-soluble binders.

We have focused here on the scientific challenges of recycling LIBs, but we recognize that the 'system performance' of the LIB recycling industry will be strongly affected by a range of non-technical factors, such as the nature of the collection, transportation, storage and logistics of LIBs at the end-of-life. As these vary from country to country and region to region, it follows that different jurisdictions may arrive at different answers to the problems posed. Research is under way in the Faraday Institution ReLiB Project, UK; the ReCell Project, US; at CSIRO in Australia and at a number of European Union projects including ReLieVe, Lithorec and Amplifll.

Recycling electric-vehicle batteries at end-of-life is essential for many reasons. At present there is little hope that profitable processes will be found for all types of current and future types of electric-vehicle LIBs without substantial successful research and development, so the imperative to recycle will derive primarily from the desire to avoid landfill and to secure the supply of strategic elements. The environmental and economic advantages of second-use and the low volume of electric-vehicle batteries currently available for recycling could stifle the development of a recycling industry in some places. In many nations, the elements and materials contained in the batteries are not available, and access to resources is crucial in ensuring a stable supply chain. Electric vehicles may prove to be a valuable secondary resource for critical materials. Carefulhusbandry of the resources consumed by electric-vehiclebattery manufacturing-and recycling-surely hold the key to the sustainability of the future automotive industry.

\section{Online content}

Any methods, additional references, Nature Research reporting summaries, source data, extended data, supplementary information, acknowledgements, peer review information; details of author contributions and competing interests; and statements of data and code availability are available at https://doi.org/10.1038/s41586-019-1682-5.

International Energy Agency (IEA) Global EV Outlook 2018 (IEA, 2018)

2. Ahmadi, L., Young, S. B., Fowler, M., Fraser, R. A. \& Achachlouei, M. A. A cascaded life cycle: reuse of electric vehicle lithium-ion battery packs in energy storage systems. Int. J. Life Cycle Assess. 22, 111-124 (2017)

3. Doughty, D. H. \& Roth, E. P. A general discussion of Li ion battery safety. Electrochem. Soc. Interface 21, 37-44 (2012).

4. Kong, L., Li, C., Jiang, J. \& Pecht, M. Li-ion battery fire hazards and safety strategies. Energies 11, 2191 (2018).

5. Rethink Waste https://www.rethinkwaste.org/uploads/media_items/111617-shorewayoperations.original.pdf (Shoreway Operations and Contract Management, 2017).

6. Reaugh, L. American Manganese: Virtual Reality International Conference (VRIC) Conversation with President and CEO Larry Reaugh - MoonShot Exec, https:// moonshotexec.com/american-manganese-vric-conversation-with-president-and-ceolarry-reaugh/ (2018).

7. Meshram, P., Pandey, B. D. \& Mankhand, T. R. Extraction of lithium from primary and secondary sources by pre-treatment, leaching and separation: a comprehensive review. Hydrometallurgy 150, 192-208 (2014).

8. Tedjar, F. in Challenge for Recycling Advanced EV Batteries https://congresses.icmab.es/ iba2013/images/files/Friday/Morning/Farouk\%20Tedjar.pdf (2013).

9. Katwala, A. The spiralling environmental cost of our lithium battery addiction. Wired https://www.wired.co.uk/article/lithium-batteries-environment-impact (2018).

10. Larcher, D. \& Tarascon, J.-M. Towards greener and more sustainable batteries for electrical energy storage. Nat. Chem. 7, 19-29 (2015).

11. Gaines, L. Lithium-ion battery recycling processes: research towards a sustainable course. Sustain. Mater. Technol. 17, e00068 (2018).

The net impact of LIB production can be greatly reduced if more materials can be recovered from end-of-life $L I B s$, in as usable a form as possible.

12. Turcheniuk, K., Bondarev, D., Singhal, V. \& Yushin, G. Ten years left to redesign lithium-ion batteries. Nature 559, 467-470 (2018).

13. Tahil, W. The Trouble with Lithium: Implications of Future PHEV Production for Lithium Demand (Meridian International Research, 2007).

14. Gaines, L. \& Nelson, P. Lithium-ion batteries: examining material demand and recycling issues. In TMS 2010 Annual Meeting and Exhibition 27-39 (TMS 2013). Initial concerns regarding resource constraints for scaling up LIB production focused on lithium; however, in the near term, reserves of lithium are unlikely to present a constraint.

15. Narins, T. P. The battery business: lithium availability and the growth of the global electric car industry. Extr. Ind. Soc. 4, 321-328 (2017).

16. Schmuch, R., Wagner, R., Hörpel, G., Placke, T. \& Winter, M. Performance and cost of materials for lithium-based rechargeable automotive batteries. Nat. Energy 3, 267 (2018).

17. Nkulu, C. B. L. et al. Sustainability of artisanal mining of cobalt in DR Congo. Nat. Sustain 1, 495 (2018).

18. Gür, T. M. Review of electrical energy storage technologies, materials and systems: challenges and prospects for large-scale grid storage. Energy Environ. Sci. 11, 2696-2767 (2018).

19. Sun, S. I., Chipperfield, A. J., Kiaee, M. \& Wills, R. G. A. Effects of market dynamics on the time-evolving price of second-life electric vehicle batteries. J. Energy Storage 19, 41-51 (2018). 
20. Gaines, L. The future of automotive lithium-ion battery recycling: charting a sustainable course. Sustain. Mater. Technol. 1-2, 2-7 (2014).

21. Jaffe, S. Vulnerable links in the lithium-ion battery supply chain. Joule 1, 225-228 (2017).

22. Helbig, C., Bradshaw, A. M., Wietschel, L., Thorenz, A. \& Tuma, A. Supply risks associated with lithium-ion battery materials. J. Clean. Prod. 172, 274-286 (2018). Focusing on six battery systems (LCO-C, LMO-C, NMC-C, NCA-C, LFP-C and LFP-LTO) this research evaluates the relative supply risk for individual elements ( $\mathrm{Li}, \mathrm{Al}, \mathrm{Ti}, \mathrm{Mn}, \mathrm{Fe}$, $\mathrm{Co}, \mathrm{Ni}, \mathrm{Cu}, \mathrm{P}$ and graphite) in LIBs.

23. Diekmann, J. et al. Ecological recycling of lithium-ion batteries from electric vehicles with focus on mechanical processes. J. Electrochem. Soc. 164, A6184-A6191 (2017).

24. Nedjalkov, A. et al. Toxic gas emissions from damaged lithium ion batteries-analysis and safety enhancement solution. Batteries 2, 5 (2016).

25. Elwert, T., Römer, F., Schneider, K., Hua, Q. \& Buchert, M. in Behaviour of Lithium-Ion Batteries in Electric Vehicles (eds Pistoia, G. \& Liaw, B.) 289-321 (Springer, 2018). This article describes the recycling and value chain of LIBs from vehicles and the different industrial approaches currently used for cell recycling, discussing the economic and ecological aspects briefly and highlighting current challenges of LIB recycling.

26. Lambert, S. M. et al. Rapid nondestructive-testing technique for in-line quality control of Li-ion batteries. IEEE Trans. Ind. Electron. 64, 4017-4026 (2017)

27. Attidekou, P. S., Wang, C., Armstrong, M., Lambert, S. M. \& Christensen, P. A. A New Time Constant Approach to Online Capacity Monitoring and Lifetime Prediction of Lithium lon Batteries for Electric Vehicles (EV). J. Electrochem. Soc. 164, A1792-A1801 (2017).

28. Attidekou, P. S. et al. A study of 40 Ah lithium ion batteries at zero percent state of charge as a function of temperature. J. Power Sources 269, 694-703 (2014).

29. Cerdas, F. et al. in Recycling of Lithium-lon Batteries 83-97 (Springer, 2018).

30. Institute of the Motor Industry (IMI) IMI Raises Skills And Regulation Concerns As Demand For Electric And Hybrid Vehicle Surges https://www.theimi.org.uk/news/imi-raises-skillsand-regulation-concerns-demand-electric-and-hybrid-vehicle-surges (IMI, 2015)

31. EVs and industrial strategy. In Electric Vehicles: Driving The Transition https://publications. parliament.uk/pa/cm201719/cmselect/cmbeis/383/38309.htm. (Business, Energy and Industrial Strategy Committee, House of Commons, UK, 2018).

32. Duflou, J. R. et al. Efficiency and feasibility of product disassembly: a case-based study. CIRPAnn. 57, 583-600 (2008)

33. Wegener, K., Chen, W. H., Dietrich, F., Dröder, K. \& Kara, S. Robot assisted disassembly for the recycling of electric vehicle batteries. Proc. CIRP 29, 716-721 (2015).

34. Dornfeld, D. A. \& Linke, B. S. (eds) Leveraging Technology for a Sustainable World. (Proc. 19th CIRP Conf. on Life Cycle Engineering) (Springer, 2012)

35. Markowski, J., Ay, P., Pempel, H. \& Müller, M. in Recycling und Rohstoffe https://www.vivis de/wp-content/uploads/RuR5/2012_RuR_443_456_Markowski.pdf (TK, 2012).

36. ReLiB. Gateway Testing \& Dismantling. https://relib.org.uk/gateway-testing-dismantling/ (The Faraday Insititution, 2019).

37. Arora, S. \& Kapoor, A. in Behaviour of Lithium-Ion Batteries in Electric Vehicles (eds Pistoia, G. \& Liaw, B.) 175-200 (Springer, 2018).

38. Chen, H. \& Shen, J. A degradation-based sorting method for lithium-ion battery reuse. PLoS One 12, e0185922 (2017).

39. Advances in Battery Technologies for Electric Vehicles (eds Bruno Scrosati, B., Jürgen Garche, J. \& Werner Tillmetz, W.) 245-263 (Elsevier, 2015).

40. Bazilian, M. D. The mineral foundation of the energy transition. Extr. Ind. Soc. 5, 93-97(2018).

41. Rujanavech, C. et al. Liam-An Innovation Story (Apple, 2016).

42. Luca, A., Albu-Schaffer, A., Haddadin, S. \& Hirzinger, G. in 2006 IEEE/RS Int. Conf. on Intelligent Robots and Systems 1623-1630 (IEEE, 2006).

43. Chapman, H., Lawton, S. \& Fitzpatrick, J. Laser cutting for nuclear decommissioning: an integrated safety approach. Atw. Int. Z. Kernenergie 63, 521-526 (2018).

44. Sun, L. et al. A novel weakly-supervised approach for RGB-D-based nuclear waste object detection. IEEE Sens. J. 19, 3487-3500 (2018).

45. Xiao, J., Stolkin, R., Gao, Y. \& Leonardis, A. Robust fusion of color and depth data for RGB-D target tracking using adaptive range-invariant depth models and spatio-temporal consistency constraints. IEEE Trans. Cybern. 48, 2485-2499 (2018).

46. Marturi, N. et al. Dynamic grasp and trajectory planning for moving objects. Auton. Robots 43, 1241-1256 (2018).

47. Ortenzi, V., Stolkin, R., Kuo, J. \& Mistry, M. Hybrid motion/force control: a review. Adv. Robot. 31, 1102-1113 (2017)

48. Adjigble, M. et al. Model-free and learning-free grasping by Local Contact Moment matching. In Int. Conf. on Intelligent Robots and Systems (IROS) 2933-2940 (IEEE, 2018). This paper presents an algorithm that is key to automated battery processing, in which an artificial intelligence and robotic vision system can autonomously plan where to place a robot's fingers to stably grasp an arbitrarily shaped object, without relying on any prior knowledge or models of the object or needing any machine learning using offline training data.

49. Pudas, J., Erkkila, A. \& Viljamaa, J. Battery recycling method. US Patent No. 8, 979, 006 (2010)

50. Hanisch, C. Recycling method for treating used batteries, in particular rechargeable batteries, and battery processing installation. US Patent Application 2019/0260101A1 (2019).

51. Smith, W. N. \& Swoffer, S. Recovery of lithium ion batteries. US Patent 8, 616, 475 (2013).

52. Li, J., Wang, G. \& Xu, Z. Generation and detection of metal ions and volatile organic compounds (VOCs) emissions from the pretreatment processes for recycling spent lithium-ion batteries. Waste Manag. 52, 221-227 (2016).

53. Shaw-Stewart, J. et al. Aqueous solution discharge of cylindrical lithium-ion cells. Sustain. Mater. Technol. https://doi.org/10.1016/j.susmat.2019.e00110 (2019)

54. Al-Thyabat, S., Nakamura, T., Shibata, E. \& lizuka, A. Adaptation of minerals processing operations for lithium-ion (LiBs) and nickel metal hydride (NiMH) batteries recycling: critical review. Miner. Eng. 45, 4-17 (2013).

55. Guo, R., Lu, L., Ouyang, M. \& Feng, X. Mechanism of the entire overdischarge process and overdischarge-induced internal short circuit in lithium-ion batteries. Sci. Rep. 6, 30248 (2016).
56. Georgi-Maschler, T., Friedrich, B., Weyhe, R., Heegn, H. \& Rutz, M. Development of a recycling process for Li-ion batteries. J. Power Sources 207, 173-182 (2012).

57. Lv, W. et al. A critical review and analysis on the recycling of spent lithium-ion batteries. ACS Sustain. Chem. Eng. 6, 1504-1521 (2018).

58. Wang, X., Gaustad, G. \& Babbitt, C. W. Targeting high value metals in lithium-ion battery recycling via shredding and size-based separation. Waste Manag. 51, 204-213 (2016).

59. Zhan, R., Oldenburg, Z.\& Pan, L. Recovery of active cathode materials from lithium-ion batteries using froth flotation. Sustain. Mater. Technol. 17, e00062 (2018).

60. Li, X., Zhang, J., Song, D., Song, J. \& Zhang, L. Direct regeneration of recycled cathode material mixture from scrapped $\mathrm{LiFePO}_{4}$ batteries. J. Power Sources 345, 78-84 (2017).

61. Li, J., Wang, G. \& Xu, Z. Environmentally-friendly oxygen-free roasting/wet magnetic separation technology for in situ recycling cobalt, lithium carbonate and graphite from spent $\mathrm{LiCoO}_{2} /$ graphite lithium batteries. J. Hazard. Mater. 302, 97-104 (2016).

62. Song, D. et al. Recovery and heat treatment of the $\mathrm{Li}\left(\mathrm{Ni}_{1 / 3} \mathrm{Co}_{1 / 3} \mathrm{Mn}_{1 / 3}\right) \mathrm{O}_{2}$ cathode scrap material for lithium ion battery. J. Power Sources 232, 348-352 (2013).

63. Chen, J. et al. Environmentally friendly recycling and effective repairing of cathode powders from spent $\mathrm{LiFePO}_{4}$ batteries. Green Chem. 18, 2500-2506 (2016).

64. Zhang, Z. et al. Ultrasound-assisted hydrothermal renovation of $\mathrm{LiCoO}_{2}$ from the cathode of spent lithium-ion batteries. Int. J. Electrochem. Sci. 9, 3691-3700 (2014).

65. Nirmale, T. C., Kale, B. B. \& Varma, A. J. A review on cellulose and lignin based binders and electrodes: small steps towards a sustainable lithium ion battery. Int. J. Biol. Macromol. 103, 1032-1043 (2017)

66. Ferreira, D. A., Prados, L. M. Z., Majuste, D. \& Mansur, M. B. Hydrometallurgical separation of aluminium, cobalt, copper and lithium from spent Li-ion batteries. J. Power Sources $187,238-246$ (2009)

67. He, L.-P., Sun, S.-Y., Song, X.-F. \& Yu, J.-G. Leaching process for recovering valuable metals from the $\mathrm{LiNi}_{1 / 3} \mathrm{Co}_{1 / 3} \mathrm{Mn}_{1 / 3} \mathrm{O}_{2}$ cathode of lithium-ion batteries. Waste Manag. 64, 171-181 (2017).

68. Li, J., Shi, P., Wang, Z., Chen, Y. \& Chang, C.-C. A combined recovery process of metals in spent lithium-ion batteries. Chemosphere 77, 1132-1136 (2009).

69. Nayaka, G. P., Pai, K. V., Santhosh, G. \& Manjanna, J. Dissolution of cathode active material of spent Li-ion batteries using tartaric acid and ascorbic acid mixture to recover Co. Hydrometallurgy 161, 54-57 (2016).

70. Pinna, E. G, Ruiz, M. C., Ojeda, W. M. \& Rodriguez, M. H. Cathodes of spent Li-ion batteries: dissolution with phosphoric acid and recovery of lithium and cobalt from leach liquors. Hydrometallurgy 167, 66-71 (2016).

71. Yang, L. et al. Preparation and magnetic performance of $\mathrm{Co}_{{ }_{0}} \mathrm{Fe}_{22} \mathrm{O}_{4}$ by a sol-gel method using cathode materials of spent Li-ion batteries. Ceram. Int. 42, 1897-1902 (2016)

72. Zheng, $X$. et al. Spent lithium-ion battery recycling-reductive ammonia leaching of metals from cathode scrap by sodium sulphite. Waste Manag. 60, 680-688 (2017).

73. Granata, G., Moscardini, E., Pagnanelli, F., Trabucco, F. \& Toro, L. Product recovery from $\mathrm{Li}$-ion battery wastes coming from an industrial pre-treatment plant: lab scale tests and process simulations. J. Power Sources 206, 393-401 (2012).

74. Mantuano, D. P., Dorella, G., Elias, R. C. A. \& Mansur, M. B. Analysis of a hydrometallurgical route to recover base metals from spent rechargeable batteries by liquid-liquid extraction with Cyanex 272. J. Power Sources 159, 1510-1518 (2006).

75. Kang, J., Senanayake, G., Sohn, J. \& Shin, S. M. Recovery of cobalt sulfate from spent lithium ion batteries by reductive leaching and solvent extraction with Cyanex 272. Hydrometallurgy 100, 168-171 (2010).

76. Kang, J., Sohn, J.-S., Chang, H., Senanayake, G. \& Shin, S. Preparation of cobalt oxide from concentrated cathode material of spent lithium ion batteries by hydrometallurgical method. Adv. Powder Technol. 21, 175-179 (2010)

77. Pagnanelli, F., Moscardini, E., Altimari, P., Abo Atia, T. \& Toro, L. Cobalt products from real waste fractions of end of life lithium ion batteries. Waste Manag. 51, 214-221 (2016)

78. Hu, C., Guo, J., Wen, J. \& Peng, Y. Preparation and electrochemical performance of nano$\mathrm{Co}_{3} \mathrm{O}_{4}$ anode materials from spent Li-ion batteries for lithium-ion batteries. J. Mater. Sci. Technol. 29, 215-220 (2013).

79. Paulino, J. F., Busnardo, N. G. \& Afonso, J. C. Recovery of valuable elements from spent Li-batteries. J. Hazard. Mater. 150, 843-849 (2008).

80. Gao, W. et al. Lithium carbonate recovery from cathode scrap of spent lithium-ion battery: a closed-loop process. Environ. Sci. Technol. 51, 1662-1669 (2017)

81. Yang, Y. et al. A closed-loop process for selective metal recovery from spent lithium iron phosphate batteries through mechanochemical activation. ACS Sustain. Chem. Eng. 5 9972-9980 (2017)

82. Wang, M.-M., Zhang, C.-C. \& Zhang, F.-S. An environmental benign process for cobalt and lithium recovery from spent lithium-ion batteries by mechanochemical approach. Waste Manag. 51, 239-244 (2016).

83. Wang, M.-M., Zhang, C.-C. \& Zhang, F.-S. Recycling of spent lithium-ion battery with polyvinyl chloride by mechanochemical process. Waste Manag. 67, 232-239 (2017).

84. Natarajan, S., Anantharaj, S., Tayade, R. J., Bajaj, H. C. \& Kundu, S. Recovered spinel $\mathrm{MnCo}_{2} \mathrm{O}_{4}$ from spent lithium-ion batteries for enhanced electrocatalytic oxygen evolution in alkaline medium. Dalton Trans. 46, 14382-14392 (2017).

85. Xi, G., Zhao, T., Wang, L., Dun, C. \& Zhang, Y. Effect of doping rare earths on magnetostriction characteristics of $\mathrm{CoFe}_{2} \mathrm{O}_{4}$ prepared from spent Li-ion batteries. Physica $B$ 534, 76-82 (2018).

86. Moura, M. N. et al. Synthesis, characterization and photocatalytic properties of nanostructured $\mathrm{CoFe}_{2} \mathrm{O}_{4}$ recycled from spent $\mathrm{Li}$-ion batteries. Chemosphere 182, 339-347 (2017).

87. $\mathrm{Li}$, J., Zhao, R., He, X. \& Liu, H. Preparation of $\mathrm{LiCoO}_{2}$ cathode materials from spent lithium-ion batteries. Ionics 15, 111-113 (2009).

88. Zou, H., Gratz, E., Apelian, D. \& Wang, Y. A novel method to recycle mixed cathode materials for lithium ion batteries. Green Chem. 15, 1183-1191 (2013)

The process is elegantly designed to remove impurities and easily tunable to synthesize the current generation of cathode materials. 


\section{Review}

89. Sa, Q. et al. Synthesis of diverse $\mathrm{LiNi}_{x} \mathrm{Mn}_{y} \mathrm{Co}_{z} \mathrm{O}_{2}$ cathode materials from lithium ion battery recovery stream. J. Sustain. Metall. 2, 248-256 (2016).

90. Yang, Y., Xu, S. \& He, Y. Lithium recycling and cathode material regeneration from acid leach liquor of spent lithium-ion battery via facile co-extraction and co-precipitation processes. Waste Manag. 64, 219-227 (2017).

91. Li, L. et al. Sustainable recovery of cathode materials from spent lithium-ion batteries using lactic acid leaching system. ACS Sustain. Chem. Eng. 5, 5224-5233 (2017).

92. Liu, Y. \& Liu, M. Reproduction of Li battery LiNi $\mathrm{Mn}_{y} \mathrm{Co}_{1-x-y} \mathrm{O}_{2}$ positive electrode material from the recycling of waste battery. Int. J. Hydrogen Energy 42, 18189-18195 (2017).

93. Nithya, C., Thirunakaran, R., Sivashanmugam, A. \& Gopukumar, S. High-performing $\mathrm{LiMg}_{x} \mathrm{Cu}_{y} \mathrm{Co}_{1-x-y} \mathrm{O}_{2}$ cathode material for lithium rechargeable batteries. ACS Appl. Mater. Interfaces 4, 4040-4046 (2012).

94. Shi, Y., Chen, G., Liu, F., Yue, X. \& Chen, Z. Resolving the compositional and structural defects of degraded $\mathrm{LiNi}_{x} \mathrm{Co}_{y} \mathrm{Mn}_{z} \mathrm{O}_{2}$ particles to directly regenerate high-performance lithium-ion battery cathodes. ACS Energy Lett. 3, 1683-1692 (2018). This paper highlights the importance of direct recycling to gain economic value from the resource.

95. Dunn, J. B., Gaines, L., Sullivan, J. \& Wang, M. Q. Impact of recycling on cradle-to-gate energy consumption and greenhouse gas emissions of automotive lithium-ion batteries. Environ. Sci. Technol. 46, 12704-12710 (2012).

This paper was one of the first to report the environmental burdens of material production, assembly and recycling of automotive LIBs in hybrid electric, plug-in hybrid electric, and battery electric vehicles.

96. Sabisch, J. E. C., Anapolsky, A., Liu, G. \& Minor, A. M. Evaluation of using pre-lithiated graphite from recycled Li-ion batteries for new LiB anodes. Resour. Conserv. Recycling 129, 129-134 (2018).

Whereas most papers focus on the recycling of valuable cathode materials, this examines the direct recycling of anode material.

97. Editorial. Recycle spent batteries. Nat. Energy 4, 253 (2019).

98. Clemens, O. \& Slater, P. R. Topochemical modifications of mixed metal oxide compounds by low-temperature fluorination routes. Rev. Inorg. Chem. 33, https://doi.org/10.1515/ revic-2013-0002 (2013)

99. Bolli, C., Guéguen, A., Mendez, M. A. \& Berg, E. J. Operando monitoring of F formation in lithium ion batteries. Chem. Mater. 31, 1258-1267 (2019).

This paper suggests that the binder (PVDF) may also contribute to cell degradation and must be taken into account when developing future recycling methodologies.

100. Karimi, G. R., Rowson, N. A. \& Hewitt, C. J. Bioleaching of copper via iron oxidation from chalcopyrite at elevated temperatures. Food Bioprod. Process. 88, 21-25 (2010).

101. Smith, S. L., Grail, B. M. \& Johnson, D. B. Reductive bioprocessing of cobalt-bearing limonitic laterites. Miner. Eng. 106, 86-90 (2017).

102. Horeh, N. B., Mousavi, S. M. \& Shojaosadati, S. A. Bioleaching of valuable metals from spent lithium-ion mobile phone batteries using Aspergillus niger. J. Power Sources 320 257-266 (2016).

103. Xin, Y. et al. Bioleaching of valuable metals $\mathrm{Li}, \mathrm{Co}, \mathrm{Ni}$ and $\mathrm{Mn}$ from spent electric vehicle Li-ion batteries for the purpose of recovery. J. Clean. Prod. 116, 249-258 (2016).
104. Mishra, D., Kim, D.-J., Ralph, D. E., Ahn, J.-G. \& Rhee, Y.-H. Bioleaching of metals from spent lithium ion secondary batteries using Acidithiobacillus ferrooxidans. Waste Manag. $\mathbf{2 8}$ 333-338 (2008)

105. Pollmann, K., Raff, J., Merroun, M., Fahmy, K. \& Selenska-Pobell, S. Metal binding by bacteria from uranium mining waste piles and its technological applications. Biotechnol. Adv. 24, 58-68 (2006)

106. Macaskie, L. E. et al. Today's wastes, tomorrow's materials for environmental protection. Hydrometallurgy 104, 483-487 (2010).

107. Ciez, R. E. \& Whitacre, J. F. Examining different recycling processes for lithium-ion batteries. Nat. Sustain. 2, 148-156 (2019).

Acknowledgements Many of the ideas suggested for recovery of high-value materials will be trialled by the Faraday Institution's ReLiB fast-start project funded by the Faraday Institution (grant numbers FIRG005 and FIRG006) and by the ReCell Center, at Argonne National Laboratory, funded by the US Department of Energy. We acknowledge the contribution to the creation of the ReLiB project of N. Rowson (Birmingham Centre for Strategic Elements and Critical Materials). We also thank Q. Dai at Argonne National Laboratories for providing additional data for Fig. 6.

Author contributions G.H. and P.A. produced the original concept of the Review, and wrote the article, integrating contributions from the team and editing and shaping the review. G.H. produced the 'Social and environmental impacts of LIBs' section. R. Somerville and E.K. collaborated on the 'Physical materials separation' and 'Stabilization and passivation of end-oflife batteries' sections; E.K. produced the 'Biological recovery' section. L.D. and P.S. produced the 'Direct recycling' section and part of the 'Hydrometallurgical metals reclamation' section. R. Stolkin and A.W. collaboratively produced the 'Automating battery assembly' section. P.C. provided contributions on safety, and safe discharging of batteries, O.H. contributed to the supply and value chain, environmental impact and economic assessments and S.L. provided information on battery re-use. A.A. and K.R. produced most of the 'Hydrometallurgical metals reclamation' section. L.G. critically revised the article. Figures 1 and 2 were created by G.H. (with help from R. Somerville and E.K.) and Fig. 4 was created by R. Somerville. Figure 3 was created by L.D., P.A. and G.H. and Fig. 6 was created by G.H. and L.G.

Competing interests The authors declare no competing interests.

Additional information

Correspondence and requests for materials should be addressed to G.H. or P.A. Peer review information Nature thanks Anand Bhatt and Matthew Lacey and the other, anonymous, reviewer(s) for their contribution to the peer review of this work. Reprints and permissions information is available at http://www.nature.com/reprints. Publisher's note Springer Nature remains neutral with regard to jurisdictional claims in published maps and institutional affiliations.

(c) Springer Nature Limited 2019 